\title{
$1 \quad$ Navigating infection risk during oviposition and larval foraging in a
}

\section{2 holometabolous insect}

3

4 Jonathon A. Siva-Jothy ${ }^{1 \S}$, Katy M. Monteith ${ }^{1 \S}$, Pedro F. Vale ${ }^{1,2^{*}}$

$5{ }^{1}$ Institute of Evolutionary Biology, School of Biological Sciences, University of Edinburgh,

6 EH9 3FL Edinburgh, United Kingdom

$7{ }^{2}$ Centre for Immunity, Infection and Evolution, University of Edinburgh, EH9 3FL Edinburgh,

8 United Kingdom

9

10 §These authors contributed equally 


\section{Abstract}

12 Deciding where to eat and raise offspring carries important fitness consequences for all 13 animals, especially if foraging, feeding and reproduction increase the risk of exposure to 14 pathogens. In insects with complete metamorphosis, foraging occurs mainly during the larval 15 stage, while oviposition decisions are taken by adult-stage females. Selection for infection 16 avoidance behaviours may therefore be developmentally uncoupled. Using a combination of 17 experimental infections and behavioural choice assays, here we tested if Drosophila 18 melanogaster fruit flies avoid potentially infectious environments at distinct developmental 19 stages. When given conspecific fly carcasses as a food source, larval-stage flies did not 20 discriminate between carcasses that were clean or infected with the pathogenic Drosophila C 21 Virus (DCV), even though scavenging was a viable route of DCV transmission. Adult females 22 however, discriminated between different oviposition sites, laying more eggs near a clean 23 rather than an infectious carcass if they were healthy; DCV-infected females did not 24 discriminate between the two environments. While potentially risky, laying eggs near 25 potentially infectious carcasses was always preferred to sites containing only fly medium. Our 26 findings suggest that infection avoidance can play an important role in how mothers provision 27 their offspring, and underline the need to consider infection avoidance behaviours at multiple 28 life-stages.

31 Key words: infection avoidance; foraging; oviposition site choice; Drosophila; Drosophila C

32 virus; infection risk 


\section{Introduction}

34 The behavioural immune system, the suite of behaviours that allow animals to avoid contact

35 with infectious environments or conspecifics, is the first line of defence against infection [1-

363 3. Avoidance of infection relies on detecting cues of parasite presence - such as visual cues of

37 infection risk or secondary pathogen metabolites - and integrating this sensory information to avoid sources of infection [4-10]. In addition to external cues of infection risk, the internal state of the animal, including its physiological status as a result of prior pathogen exposure, may also affect the ability to detect and avoid infection [11-13].

Avoiding contact with pathogens allows healthy individuals to escape the pathology that results from infection, and also prevents the deployment of the immune response, which may be metabolically costly and even cause immunopathology $[2,3,14]$. Despite these clear advantages, avoiding infection completely is rarely possible. Foraging and feeding, for example, are vital aspects of host metabolism, and are key to organismal reproduction and fitness, but they are also major routes of pathogen transmission $[15,16]$.

Foraging and feeding are particularly important for holometabolous insect larvae, which devote most of their time to these behaviours. In situations of severe nutritional scarcity, larvae may even resort to cannibalism. For example, larvae of the fruit fly Drosophila melanogaster readily eat the carcasses of conspecifics following periods of starvation $[17,18]$. Cannibalism may appear to be a beneficial strategy when the alternative is starvation, but may increase the risk of trophic transmission of pathogens and parasites, especially if infected individuals are more likely to be targeted for cannibalism. While larvae of many insect species are frequently observed to avoid infectious environments or food sources [19], it is currently unclear if trophic infection avoidance occurs during cannibalistic scavenging. 
59 Beyond foraging during the larval stage, choosing where to oviposit or rear offspring is another

60 important life-history decision, but can be risky if individuals are unable to identify and avoid

61 potentially infectious environments. The environment in which adult insects choose to oviposit

62 is therefore a major determinant both of offspring environmental quality and infection risk

$63[7,16,20]$. Infection avoidance by insects during oviposition has been observed in response to

64 a number of parasites and appears to be driven by diverse sensory cues, including avoidance

65 of parasitoid wasp visual cues [7], and olfactory detection of bacteria and fungi [6,10].

66 Together, both adult oviposition choice and larval food preference determine the likelihood of

67 infection in the early life-stages of holometabolous insects, and therefore both behaviours play an important role in disease transmission dynamics [4,21].

69

Here, we investigate larval foraging and adult oviposition in a holometabolous insect - the fruit

fly Drosophila melanogaster - in the context of infection avoidance. Our study consisted of choice assays performed on either larval or adult stage D. melanogaster. Fly larvae were presented with a choice of scavenging on either a clean, non-infectious adult fly carcass, or a carcass that had been previously inoculated with a systemic Drosophila C Virus (DCV) infection (Figure 1a). In a second experiment, we tested adult oviposition choice by giving female flies the choice to lay eggs on a clean food source, a clean food source also containing a clean carcass, and a food source containing a carcass with a systemic DCV infection (Figure 1b). This 3-way choice assay allowed us to examine an important conflict faced by mothers: a carcass may present an additional nutritional source for future offspring, but may also present a potential risk of infection. In both experiments we assessed the fitness consequences of choices at both life-stages by following the development and longevity of larva (or laid eggs) as adult flies. 
83

84

85

86

87

88

89

90

91

92

93

94

95

96

97

98

99

100

101

102

103

104

105

106

\section{Materials and Methods}

\section{Fly lines and rearing conditions}

Both experiments used laboratory stocks of D.melanogaster Oregon R (OreR). Fly stocks were kept in plastic bottles (6oz; Genesee Scientific, San Diego, California, US) on a standard diet of Lewis medium [22] at $18 \pm 1^{\circ} \mathrm{C}$ with a 12 hour light:dark cycle. Stocks were tipped approximately every 21 days into new bottles. Before the experiments, flies were transferred to clean bottles and maintained at low density ( $\sim 50$ flies per bottle) for a minimum of two generations at $25 \pm 1^{\circ} \mathrm{C}$ with a 12 hour light:dark cycle.

\section{Virus culture and infection}

Drosophila C Virus (DCV) is a horizontally transmitted positive-sense ssRNA virus of the Dicistroviridae family [23]. DCV infection establishes in the digestive, reproductive and fat tissues, resulting in a range of behavioural and physiological pathologies in both larval and adult stage flies, including reduced locomotor activity, metabolic and reproductive dysfunction, and eventually death [24-28]. The DCV isolate used in this experiment was originally isolated in Charolles, France [29] and was grown in Schneider Drosophila Line 2 (DL2) as previously described [27], serially diluted ten-fold in TRIS-HCl solution ( $\mathrm{pH}=7.3)$, aliquoted and frozen at $-80^{\circ} \mathrm{C}$ until required. To infect flies, Austerlitz insect pins $(0.15 \mathrm{~mm}$ in diameter) were bent at a $90^{\circ}$ angle $\sim 0.5 \mathrm{~mm}$ from the tip, dipped in DCV $\left(10^{8}\right.$ infectious units (IU) per ml), and inserted into the pleural suture of flies under $\mathrm{CO}_{2}$ anaesthesia. Control infections employed the same protocol but with a needle tip dipped in sterile TRIS solution. 


\section{Infection avoidance during larval foraging}

108 We first tested if fly larvae could discriminate between healthy and potentially infectious fly carcasses. To generate these carcasses 4-7 day old male and female flies were randomly

110 selected from an age-matched population. For each sex, half of the flies were stabbed with

111 DCV $10^{7} \mathrm{DCV}$ copies/ml and the other half stabbed with sterile TRIS buffer. Following 6 days

112 (to allow viral replication), flies were frozen at $-80{ }^{\circ} \mathrm{C}$ until required. We confirmed the 113 infection status of the carcasses using DCV-specific qRT-PCR(see below) by randomly 114 picking 5 male and 5 female flies.

116 We carried out a two-choice assay by placing $~ 100$ fly eggs at the centre of each Petri dish 117 containing $\sim 20 \mathrm{ml}$ solid agar (5\% sugar), and allowed the resulting $3^{\text {rd }}$ instar larvae to forage 118 towards either a clean fly carcass or a carcass infected with DCV, placed at an equidistant 119 positon from the eggs $(3 \mathrm{~cm})$. We set up 56 'choice' assays where larvae could choose between a clean or DCV infected carcass, and 20 'control' assays, where both carcasses were clean (half of assays contained male carcasses, and the other half contained female carcasses). To differentiate between any effects of carcass degradation from a direct effect of DCV presence on larval choice, we also set up an additional 30 plates without fly carcasses, containing $10 \mu 1$ of DCV (107 DCV IU/ml) and $10 \mu 1$ of TRIS (two-choice; $\mathrm{N}=20$ ) or only TRIS (control; $\mathrm{N}=10$ ). 18 of the 106 plates set up across all treatments were excluded from the final dataset due to damage to the agar discriminating larval movement and thus providing unreliable results. All assays were conducted at $25 \pm 1{ }^{\circ} \mathrm{C}$ with a 12 -hour light:dark cycle before being photographed after 72 hours. Images were marked using Adobe Photoshop CS3 to count the number of larvae 
132

133

134

135

136

137

138

139

140

141

142

143

144

\section{Larval infection status and virus quantification}

We randomly selected 10 wandering-stage larvae found immediately adjacent to each carcass in 20 'choice plates' and one carcass in 6 'control plates' to assess DCV infection status and quantify viral load. Viral quantification was carried out by absolute quantification of DCV RNA copies using qRT-PCR. Total RNA was extracted by homogenising the flies or larvae in TRI Reagent (Invitrogen, Carlsbad, California, US) and using Direct-zol RNA miniprep kit (Zymo Research, Irvine, California, US), including a DNase step. The eluted RNA was then reverse-transcribed with M-MLV reverse transcriptase (Promega, Madison, Wisconsin, US) and random hexamer primers, and then diluted 1:1 with nuclease free water. The qRT-PCR was performed on an Applied Biosystems StepOnePlus system using Fast SYBR Green Master Mix (Applied Biosystems, Foster City, California, US) using the following forward and reverse primers, which include 5'-AT rich flaps to improve fluorescence [30] (DCV_Forward: 5' AATAAATCATAAGCCACTGTGATTGATACAACAGAC 3'; DCV_Reverse: 5' AATAAATCATAAGAAGCACGATACTTCTTCCAAACC 3'; with the following PCR cycle: $95^{\circ} \mathrm{C}$ for $2 \mathrm{~min}$ followed by 40 cycles of: $95^{\circ} \mathrm{C}$ for $10 \mathrm{sec}$ followed by $60^{\circ} \mathrm{C}$ for $30 \mathrm{sec}$. Two qRT-PCR reactions (technical replicates) were carried out per sample.

For absolute quantification of DCV, the concentrations of DCV in the samples were extrapolated from a standard curve created from a 10-fold serial dilution (1-10-6) of DCV cDNA.

\section{Larval development and infection status}

To analyse the effect of foraging choice on larval development, we removed 15 larvae found within $2 \mathrm{~cm}$ of each carcass from 20 'choice' plates and from one carcass on 6 'control' plates. Larvae from each carcass were transferred together into plastic vials containing Lewis medium 
and we recorded the number of larvae that developed into pupae and the number of eclosed adults.

\section{Infection avoidance during oviposition}

160 Following our test of infection avoidance at the larval stage, we tested the oviposition preference of female D. melanogaster when presented with a choice of clean and potentially infectious oviposition sites. Choice chambers were constructed by joining two lids of transparent plastic Petri dishes with adhesive tape, making a chamber $10 \mathrm{~cm}$ in diameter and 2 $\mathrm{cm}$ in height. Chambers contained three oviposition sites comprised of upturned caps filled with Lewis medium, arranged in a triangle, each site, $50 \mathrm{~mm}$ from the other two (Figure $1 \mathrm{~b}$ ).

Three-day-old flies ( $N=40$ males and 40 females) were isolated as virgins and stabbed with a virus-contaminated or sterile, virus-free control solution. Following infection, flies to be used in the oviposition assay were introduced to two males for mating for 72 hours. We then introduced a single mated female fly to each chamber and placed at $25^{\circ} \mathrm{C}$ (12-hour light:dark cycle) to allow oviposition. Two females (1 infected and 1 uninfected) laid no eggs during the experiment so were excluded from the final dataset. In total, we analysed the oviposition

175 choice of 78 females. As DCV has been reported to affect D. melanogaster fecundity, to account for differences in the total number of eggs laid by our infection treatment group we

177 measured oviposition site choice by counting the number of eggs at each site rather than the 178 proportion of eggs laid at the three respective sites. To count the number of eggs laid on each 179 oviposition site, photos were taken of individual oviposition sites with a Leica MC170 HD 
camera attachment on a Leica 0.32x/WD 200mm S8APO microscope (Leica microsystems,

Wetzlar, Germany) after 24 and 48 hours.

\section{Fitness consequences of oviposition site choice}

184 We quantified the potential fitness consequences of oviposition preference by transferring all oviposition sites, including carcass (if present), to individual vials and recorded egg-to-adult viability. Adults that eclosed from clutches during this experiment were frozen alongside in

TRI reagent and DCV infection analysed using the same protocol as above. A total of 24 clutches were analysed in this way, with 6 oviposition sites excluded due to degradation or contamination during qPCR preparation.

\section{Statistical Analyses}

192 In the larval choice experiment, we analysed the proportion of larvae choosing a given plate

193 half or carcass area; larval DCV titers; the proportion of larvae developing into pupae (logit transformed); and the proportion of pupae that developed into adult flies (logit transformed). experiment, we used the number of eggs laid at each oviposition site to assess infection avoidance. We analysed eggs counts, rather than the proportion of eggs laid on each oviposition site, to account for potential differences in fecundity between infected and uninfected flies (e.g. distributed error. The oviposition site, infection status of the fly as well as an interaction between the two were listed as fixed effects. The total number of eggs laid and the choice 
to account for repeated measures and non-independence. The proportion of eggs that later graphics were carried out and produced in R 3.3.0 using the ggplot 2 , lme4 and multcomp packages.

\section{Results}

\section{Larval flies do not avoid infectious food sources when scavenging}

213 Fly larvae that hatched from eggs placed in the centre of the Petri dish, dispersed towards and consumed the fly carcasses placed at the edges of the dish (Video S1). We found no evidence half larvae were found in or the area surrounding each carcass or TRIS droplet) larvae showed no significant preference for clean or infected fly carcasses (Figures 2a, 2b; Table 1).

\section{DCV is transmitted to larvae when scavenging on infected carcasses}

DCV was detected in larvae collected from plates containing an infected carcass (Figure 3a,

Table 1), confirming that scavenging infected carcasses is a viable route of virus transmission.

222 As expected, larvae surrounding DCV-infected carcasses were found to have significantly higher DCV titres when compared to larvae collected from control plates (which contained only uninfected carcasses). However, we also detected DCV infection in larvae surrounding clean carcasses that were housed in a two-choice plate (containing both infected and uninfected carcasses) (Figure 3a), suggesting that some larvae may have moved between food sources in these plates during the assay. 


\section{No effect of virus transmission on larval development}

230 Acquiring infection by scavenging on infectious carcasses had no detectable effect on larval

231 development into pupae (Figure 3b), or in the proportion of pupae that eclosed as adults (Figure

232 3c; Table 1). However, larval development to pupal stage was significantly higher in larvae

233 that had fed on female carcasses (Figure 3b; Table 1): 50\% of larvae feeding on female carcasses reached pupation, while a significantly lower proportion $(32 \%)$ reached pupation if sex or infection status on the proportion of pupae that eclosed as adults (Figure 3c, Table 1).

\section{Virus acquired during the larval stage can persist into adulthood}

We measured DCV titres in flies that eclosed as adults (Figure 3d). While no DCV infection adult flies that were collected from infected carcasses, suggesting that DCV infection can persist through metamorphosis into the adult insect stage.

\section{Oviposition preference changes over time and depends on the female's infection status}

245 Female flies showed a clear preference for oviposition sites containing a carcass, but this

246 choice depended on the fly infection status (Figure 4a, 4b; Table 2). Within the first 24-hour

247 period, uninfected female flies laid significantly more eggs at sites containing a clean carcass compared to sites with an infected carcass or just food (Figure 4a). Female flies infected with observation period, uninfected females still laid more eggs at sites with carcasses, but no 
but laid even more eggs on sites containing an infected carcass (pairwise contrast, $\mathrm{p}<0.001$ )

255 (Figure 4b).

257 Fitness consequences of oviposition preference

258 Egg-to-Adult viability differed significantly between oviposition sites, and was lower in

259 food-only sites compared to sites containing a carcass (Figure 4c; Table 2). Clutches

260 emerging at carcass sites however, did not differ in their egg-to-adult viability (Figure 4c;

Table 2), even though we detected DCV within flies that developed around DCV-infected carcasses (Figure 4d). The infection status of mothers had no effect on egg-to-adult viability (Figure 4c; Table 2) or on the viral load of these clutches (Figure 4d; Table 2).

\section{Discussion}

267 Viral infection is widespread among invertebrates [32,33], and can cause considerable morbidity and mortality $[24,28,34,35]$. We should therefore expect selection for mechanisms that allow hosts to detect and avoid infectious conspecifics or potentially infectious environments $[3,4]$. In the present work, we examined how larval foraging and adult oviposition in D. melanogaster are modified in the presence of potential infection by the horizontally transmitted Drosophila C virus (DCV), which is known to cause a variety of physiological and behavioural pathology in fruit flies [24-28].

Our results confirm previous findings that Drosophila larvae will actively cannibalise conspecific carcasses when placed in a nutrient-poor environment $[17,18]$, and go further to demonstrate that necrophagy is a viable route for transmission of Drosophila $\mathrm{C}$ Virus. The consumption of infectious conspecifics, either through cannibalism or necrophagy, has been 
insect species [36-40]. In holometabolous insects, this phenomenon has been particularly well investigated in Lepidoptera, where cannibalism and/or necrophagy of infected conspecifics has also shown to be a viable route of transmission of several viruses during larval development $[39,41-44]$.

Despite the risk of acquiring infection during cannibalistic foraging, we found no evidence that larval-stage flies could discriminate and avoid infectious carcasses from clean ones. Our findings contrast with a recent study in which Drosophila larvae showed evasion of food containing a bacterial suspension of virulent Pseudomonas entomophila [45]. Avoidance was no longer observed when using a less virulent strain of the bacterial pathogen, suggesting that external cues about the relative risk and severity of infection are key to avoidance behaviours. al (2017) tested evasion in $1^{\text {st }}$ instar larvae, in the current study larval foraging choice was recorded during the $3^{\text {rd }}$ instar, as this is the period of development when foraging activity and feeding is known to peak [46]. Given that larvae are known to actively migrate towards higher quality food [47], the lack of trophic infection avoidance suggests that selection for avoidance of this viral infection is weak. Weak selection for avoidance would be expected if, for example, the fitness costs of DCV infection are low during larval stage infection.

Our data is consistent with a low cost of infection in larvae, as the low titres of DCV acquired during larval feeding on carcasses did not have severe consequences for larval development.

302 Our results contrast with a previous study on DCV infection of larval D. melanogaster which reported a $14 \%$ reduction in egg-to-adult viability, and severe mortality in adults emerged from 
305 DCV-infected flies, and exposed continuously during development until 4-days post-eclosion.

306 This difference in viral exposure may explain the more severe costs of DCV infection

307 compared to this study.

308

309 In contrast to the lack of discrimination seen during larval foraging, we found that adult

310 female flies do discriminate between different types of oviposition sites. Uninfected female

311 flies laid more eggs on sites containing an uninfected or infected carcass and food, than a site

312 comprised only of food despite the infection risk this presents. One possible reason for this

313 apparently risky strategy is that while a conspecific carcass can present an infection risk it is

314 also a potential source of additional nutrition [48]. Starved D. melanogaster larvae assess the

315 nutritional value of carcasses, ranging from conspecifics to natural predators (Ahmad et al.,

316 2015), and tune their foraging strategies accordingly to optimally forage. Clutches developing

317 on oviposition sites with a carcass present had significantly higher egg-to-adult viability than

318 food only sites (Figure 4c). The preference we see for oviposition sites containing a carcass

319 may therefore indicate that the nutritional value of carcasses on the oviposition sites, rather

320 than infection risk, is driving oviposition-site preference.

321

322 During the first 24 hours of egg laying, uninfected flies laid significantly more eggs around

323 uninfected carcasses. This suggests that the presence of DCV is being detected and avoided

324 during oviposition. It is unclear which cues of DCV are detected by females, whether they are

325 detecting the virus directly, or cues of virus derived pathology in the fly carcass. Similar

326 avoidance of pathogenic bacteria has been described in both $D$. melanogaster $[6,8,10]$ and $C$.

327 elegans [49,50]. Avoidance of virus infection has also been described in a range of

328 invertebrates, such as gypsy moth larvae that avoid eating leaves contaminated with virus [51] 
and lobsters that avoid virus-infected conspecifics [52]. This avoidance likely relies on dedicated chemosensory pathways for olfactory cues $[6,9,10,49]$.

332 Following the initial 24-hour period, this preference for uninfected carcasses was no longer observed (Figure 4b). We interpret this shift in oviposition-site preference as the result of a trade-off faced by females between minimising DCV infection risk and maximising fecundity. The finite nutritional value of each oviposition site dictates an optimal clutch size that each site can support. If females exceed this, fewer resources are available per offspring. As uninfected

337 flies laid more eggs on non-infectious carcass sites in the first 24 hours, the optimal clutch size is approached sooner than the other two sites. Fruit flies integrate the nutritional quality of oviposition sites into deciding between laying more eggs and acquiring more resources to develop more eggs [53], a trade-off that is also seen in a range of other organisms [48,53-55]. In order to maximise the number of eggs laid, females therefore appear to risk DCV infection by laying their eggs near an infected carcass. The relative nutritional value and the potential costs of DCV infection are patent in the egg-to-adult viability of offspring from each oviposition site: the increase in viability between the food-only site and both the uninfected and infected carcass sites reflects the nutritional difference between these sites. As is clear from

346 Figure 4c, the benefits of oviposition near any carcass appear to outweigh the potential costs of virus infection.

In contrast to uninfected females, females infected with DCV did not discriminate between infectious and non-infectious carcasses, laying the same number of eggs in either oviposition

351 site (Figure 4a,b). Furthermore, in the second 24-hour period, infected females laid significantly more eggs at infectious carcass sites. We interpret this difference in discrimination 
infection risk. For infected females already paying the cost of infection, there is little benefit from avoiding infectious sites.

In summary, our results show that D. melanogaster larvae and adults respond to infection risk differently during foraging and oviposition. Notably, oviposition site choice was affected by the female's infection status and the time-dependent nutritional value of oviposition sites. The initial DCV avoidance shown by mothers during oviposition may also explain why larvae do not avoid DCV during foraging. Alongside a relatively low cost of infection, larvae simply may not need to avoid infection because their mothers have evolved to avoid infectious sites where possible during oviposition. As larvae are not able to forage over large distances, their development - and ultimately their fitness - relies heavily on their mother's capacity to pick the environment that maximises nutritional value while minimising the risk of infection.

\section{References}

1. Parker BJ, Barribeau SM, Laughton AM, de Roode JC, Gerardo NM. 2011 Nonimmunological defense in an evolutionary framework. Trends Ecol. Evol. 26, 242-248. (doi:10.1016/j.tree.2011.02.005)

2. Schaller M, Park JH. 2011 The Behavioral Immune System (and Why It Matters). Curr.

3. Curtis VA. 2014 Infection-avoidance behaviour in humans and other animals. Trends

4. Kiesecker JM, Skelly DK, Beard KH, Preisser E. 1999 Behavioral reduction of infection risk. Proc. Natl. Acad. Sci. 96, 9165-9168. (doi:10.1073/pnas.96.16.9165)

5. Kavaliers M, Choleris E, Ågmo A, Pfaff DW. 2004 Olfactory-mediated parasite recognition and avoidance: linking genes to behavior. Horm. Behav. 46, 272-283. (doi:10.1016/j.yhbeh.2004.03.005) 
382

383

384

385

386

387

388

389

390

391

392

393

394

395

396

397

398

399

400

401

402

403

404

405

406

407

408

409

410

411

412

413

414

415

416

7. Kacsoh BZ, Lynch ZR, Mortimer NT, Schlenke T a. 2013 Fruit flies medicate offspring after seeing parasites. Science 339, 947-50. (doi:10.1126/science.1229625)

8. Babin A, Kolly S, Schneider F, Dolivo V, Zini M, Kawecki TJ. 2014 Fruit flies learn to avoid odours associated with virulent infection. Biol. Lett. 10, 20140048.

(doi:10.1098/rsbl.2014.0048)

9. Meisel JD, Panda O, Mahanti P, Schroeder FC, Kim DH. 2014 Chemosensation of Bacterial Secondary Metabolites Modulates Neuroendocrine Signaling and Behavior of C. elegans. Cell 159, 267-280. (doi:10.1016/j.cell.2014.09.011)

10. Kurz CL, Charroux B, Chaduli D, Viallat-Lieutaud A, Royet J. 2017 Peptidoglycan sensing by octopaminergic neurons modulates Drosophila oviposition. eLife 6. (doi:10.7554/eLife.21937)

11. Curtis V, de Barra M, Aunger R. 2011 Disgust as an adaptive system for disease avoidance behaviour. Philos. Trans. R. Soc. Lond. B. Biol. Sci. 366, 389-401. (doi:10.1098/rstb.2010.0117)

12. Klemme I, Karvonen A. 2016 Learned parasite avoidance is driven by host personality and resistance to infection in a fish-trematode interaction. Proc. R. Soc. Lond. B Biol. Sci. 283.

13. Vale PF, Jardine MD. 2016 Viral exposure reduces the motivation to forage in female Drosophila melanogaster. Fly (Austin) , 1-7. (doi:10.1080/19336934.2016.1207029)

14. Sears BF, Rohr JR, Allen JE, Martin LB. 2011 The economy of inflammation: when is less more? Trends Parasitol. 27, 382-387. (doi:10.1016/j.pt.2011.05.004)

15. Hall SR, Sivars-Becker L, Becker C, Duffy MA, Tessier AJ, Cáceres CE. 2007 Eating yourself sick: transmission of disease as a function of foraging ecology. Ecol. Lett. 10, 207-218. (doi:10.1111/j.1461-0248.2007.01011.x)

16. Lefèvre T, de Roode JC, Kacsoh BZ, Schlenke TA. 2011 Defence strategies against a parasitoid wasp in Drosophila: fight or flight? Biol. Lett. (doi:10.1098/rsbl.2011.0725)

17. Vijendravarma RK, Narasimha S, Kawecki TJ. 2013 Predatory cannibalism in Drosophila melanogaster larvae. Nat. Commun. 4, 1789. (doi:10.1038/ncomms2744)

18. Ahmad M, Chaudhary SU, Afzal AJ, Tariq M. 2015 Starvation-Induced Dietary Behaviour in Drosophila melanogaster Larvae and Adults. Sci. Rep. 5, 14285.

(doi:10.1038/srep14285)

19. de Roode JC, Lefèvre T. 2012 Behavioral Immunity in Insects. Insects 3, 789-820. (doi:10.3390/insects3030789)

20. Lefèvre T et al. 2012 Behavioural resistance against a protozoan parasite in the monarch butterfly. J. Anim. Ecol. 81, 70-79. (doi:10.1111/j.1365-2656.2011.01901.x) 
417

418

419

420

421

422

423

424

425

426

427

428

429

430

431

432

433

434

435

436

437

438

439

440

441

442

443

444

445

446

447

448

449

450

451

21. Ezenwa VO, Archie EA, Craft ME, Hawley DM, Martin LB, Moore J, White L. 2016 Host behaviour-parasite feedback: an essential link between animal behaviour and disease ecology. Proc R Soc B 283, 20153078. (doi:10.1098/rspb.2015.3078)

22. Lewis E. 2014 A new standard food medium. 1960 Drosophila Information Service. in. Cold Spring Harb. Protoc. 2014, pdb.rec081414. (doi:10.1101/pdb.rec081414)

23. Huszar T, Imler J. 2008 Drosophila Viruses and the Study of Antiviral Host-Defense. In Advances in Virus Research, pp. 227-265. Academic Press.

24. Arnold PA, Johnson KN, White CR. 2013 Physiological and metabolic consequences of viral infection in Drosophila melanogaster. J. Exp. Biol. 216, 3350-3357.

(doi:10.1242/jeb.088138)

25. Chtarbanova S et al. 2014 Drosophila C virus systemic infection leads to intestinal obstruction. J. Virol. 88, 14057-14069. (doi:10.1128/JVI.02320-14)

26. Stevanovic A, Johnson KN. 2015 Infectivity of Drosophila C virus following oral delivery in Drosophila larvae. J. Gen. Virol. (doi:10.1099/vir.0.000068)

27. Vale PF, Jardine MD. 2015 Sex-specific behavioural symptoms of viral gut infection and Wolbachia in Drosophila melanogaster. J. Insect Physiol. 82, 28-32. (doi:10.1016/j.jinsphys.2015.08.005)

28. Gupta V, Stewart C, Rund SS., Monteith K, Vale PF. 2017 Costs and benefits of sub-lethal Drosophila C virus infection. J. Evol. Biol. (doi:10.1111/jeb.13096)

29. Jousset F-X, Bergoin M, Revet B. 1977 Characterization of the Drosophila C Virus. J. Gen. Virol. 34, 269-283. (doi:10.1099/0022-1317-34-2-269)

30. Afonina I, Ankoudinova I, Mills A, Lokhov S, Huynh P, Mahoney W. 2007 Primers with 5' flaps improve real-time PCR. BioTechniques 43, 770, 772, 774.

31. Gomariz-Zilber E, Thomas-Orillard M. 1993 Drosophila C virus and Drosophila hosts: a good association in various environments. J. Evol. Biol. 6, 677-689. (doi:10.1046/j.14209101.1993.6050677.x)

32. Webster CL et al. 2015 The Discovery, Distribution, and Evolution of Viruses Associated with Drosophila melanogaster. PLoS Biol 13, e1002210.

(doi:10.1371/journal.pbio.1002210)

33. Shi M et al. 2016 Redefining the invertebrate RNA virosphere. Nature 540, 539-543. (doi:10.1038/nature20167)

34. Escobedo-Bonilla CM, Alday-Sanz V, Wille M, Sorgeloos P, Pensaert MB, Nauwynck HJ. 2008 A review on the morphology, molecular characterization, morphogenesis and pathogenesis of white spot syndrome virus. J. Fish Dis. 31, 1-18. (doi:10.1111/j.13652761.2007.00877.x) 
452

453

454

455

456

457

458

459

460

461

462

463

464

465

466

467

468

469

470

471

472

473

474

475

476

477

478

479

480

481

482

483

484

485

486

487

488

35. Wilfert L, Long G, Leggett HC, Schmid-Hempel P, Butlin R, Martin SJM, Boots M. 2016 Deformed wing virus is a recent global epidemic in honeybees driven by Varroa mites. Science 351, 594-597. (doi:10.1126/science.aac9976)

36. Forbes LB. 2000 The occurrence and ecology of Trichinella in marine mammals. Vet. Parasitol. 93, 321-334. (doi:10.1016/S0304-4017(00)00349-6)

37. Qureshi T, Labes RE, Lambeth M, Montgomery H, Griffin JFT, Mackintosh CG. 2000 Transmission of Mycobacterium bovis from experimentally infected ferrets to noninfected ferrets ( Mustela furo ). N. Z. Vet. J. 48, 99-104. (doi:10.1080/00480169.2000.36173)

38. Pearman PB, Garner TWJ, Straub M, Greber UF. 2004 Response of the Italian agile frog (Rana latastei) to a Ranavirus, frog virus 3: a model for viral emergence in naïve populations. J. WildI. Dis. 40, 660-669. (doi:10.7589/0090-3558-40.4.660)

39. Williams T, Hernández O. 2006 Costs of cannibalism in the presence of an iridovirus pathogen of Spodoptera frugiperda. Ecol. Entomol. 31, 106-113. (doi:10.1111/j.03076946.2006.00771.x)

40. Alpers MP. 2008 The epidemiology of kuru: monitoring the epidemic from its peak to its end. Philos. Trans. R. Soc. B Biol. Sci. 363, 3707-3713. (doi:10.1098/rstb.2008.0071)

41. Dhandapani N, Jayaraj S, Rabindra RJ. 1993 Cannibalism on nuclear polyhedrosis virus infected larvae by $<$ span class='italic' $>$ Heliothis armigera $</$ span $>$ (Hubn.) and its effect on viral infection. Int. J. Trop. Insect Sci. 14, 427-430.

(doi:10.1017/S1742758400014089)

42. Vasconcelos SD. 1996 Alternative Routes for the Horizontal Transmission of a Nucleopolyhedrovirus. J. Invertebr. Pathol. 68, 269-274. (doi:10.1006/jipa.1996.0095)

43. Boots M. 1998 Cannibalism and the stage-dependent transmission of a viral pathogen of the Indian meal moth, Plodia interpunctella. Ecol. Entomol. 23, 118-122.

(doi:10.1046/j.1365-2311.1998.00115.x)

44. Elvira S, Williams T, Caballero P. 2010 Juvenile Hormone Analog Technology: Effects on Larval Cannibalism and the Production of $\langle 1>$ Spodoptera exigua $</|>$ (Lepidoptera:

Noctuidae) Nucleopolyhedrovirus. J. Econ. Entomol. 103, 577-582.

(doi:10.1603/EC09325)

45. Surendran S, H?ckesfeld S, W?schle B, Pankratz MJ. 2017 Pathogen-induced food evasion behavior in Drosophila larvae. J. Exp. Biol. 220, 1774-1780.

(doi:10.1242/jeb.153395)

46. Sokolowski MB. 2001 Drosophila: Genetics meets behaviour. Nat. Rev. Genet. 2, 879890. (doi:10.1038/35098592)

47. Durisko Z, Dukas R. 2013 Attraction to and learning from social cues in fruitfly larvae. Proc. R. Soc. B Biol. Sci. 280, 20131398-20131398. (doi:10.1098/rspb.2013.1398) 
489

490

491

492

493

494

495

496

497

498

499

500

501

502

503

504

505

506

507

508

509

510

511

512

48. Albeny-Sim?es D, Murrell EG, Elliot SL, Andrade MR, Lima E, Juliano SA, Vilela EF. 2014 Attracted to the enemy: Aedes aegypti prefers oviposition sites with predator-killed conspecifics. Oecologia 175, 481-492. (doi:10.1007/s00442-014-2910-1)

49. McMullan R, Anderson A, Nurrish S. 2012 Behavioral and Immune Responses to Infection Require Gaq- RhoA Signaling in C. elegans. PLOS Pathog. 8, e1002530. (doi:10.1371/journal.ppat.1002530)

50. Meisel JD, Kim DH. 2014 Behavioral avoidance of pathogenic bacteria by Caenorhabditis elegans. Trends Immunol. 35, 465-70. (doi:10.1016/j.it.2014.08.008)

51. Parker BJ, Elderd BD, Dwyer G. 2010 Host behaviour and exposure risk in an insectpathogen interaction. J. Anim. Ecol. 79, 863-870. (doi:10.1111/j.13652656.2010.01690.x)

52. Behringer DC, Butler MJ, Shields JD. 2006 Ecology: avoidance of disease by social lobsters. Nature 441, 421. (doi:10.1038/441421a)

53. Lihoreau M, Poissonnier L-A, Isabel G, Dussutour A. 2016 Drosophila females trade off good nutrition with high-quality oviposition sites when choosing foods. J. Exp. Biol. 219.

54. Blaustein L. 1999 Oviposition Site Selection in Response to Risk of Predation: Evidence from Aquatic Habitats and Consequences for Population Dynamics and Community Structure. In Evolutionary Theory and Processes: Modern Perspectives (ed SP Wasser), pp. 441-456. Springer Netherlands. (doi:10.1007/978-94-011-4830-6_26)

55. Tjørnløv RS, Kissling WD, Barnagaud J-Y, Bøcher PK, Høye TT. 2015 Oviposition site selection of an endangered butterfly at local spatial scales. J. Insect Conserv. 19, 377391. (doi:10.1007/s10841-014-9747-0) 


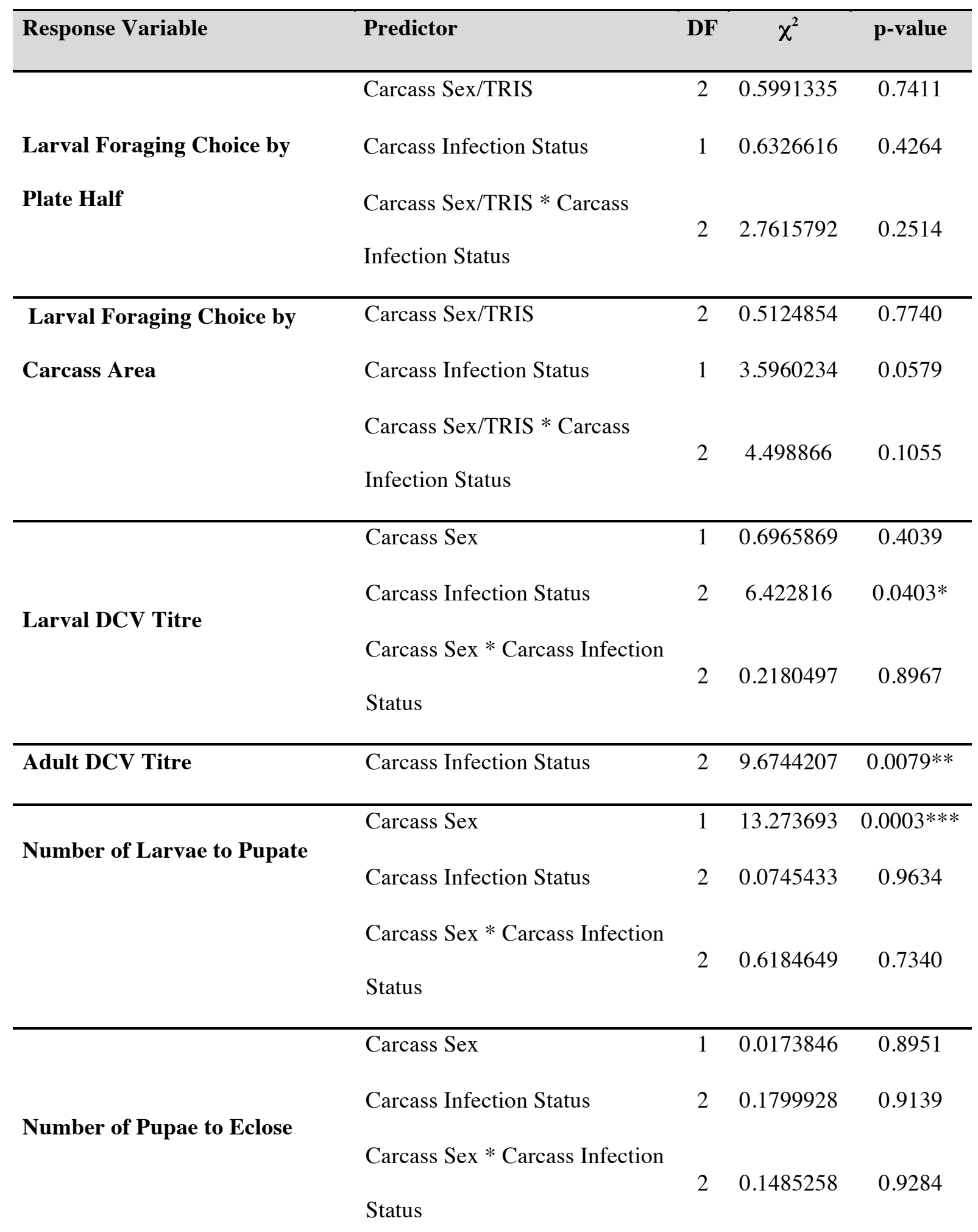

514 Table 1. Model outputs for statistical tests performed on all experiments testing the causes and costs

515 of infection avoidance in D. melanogaster larval foraging. Significant predictors are marked with

516 asterisks $\left(\mathrm{p}<0.05=^{*}, \mathrm{p}<0.01=* *\right.$ and $\left.\mathrm{p}<0.001=* * *\right)$. 


\begin{tabular}{|c|c|c|c|c|}
\hline Response Variable & Predictor & $\overline{D F}$ & F-ratio & p-value \\
\hline \multirow{4}{*}{ Eggs Laid 0-24 hours } & Oviposition Site & 2 & 133.2992 & $<0.0001^{* * *}$ \\
\hline & Maternal Infection Status & 1 & 1.1512 & 0.292 \\
\hline & Oviposition Site * Maternal Infection & & & \\
\hline & Status & 2 & 6.5983 & $0.0042^{* *}$ \\
\hline \multirow{4}{*}{ Eggs Laid 24-48 hours } & Oviposition Site & 2 & 108.039 & $<0.0001 * * *$ \\
\hline & Maternal Infection Status & 1 & 0.00001 & 0.99 \\
\hline & Oviposition Site * Maternal Infection & & & \\
\hline & Status & 2 & $11.2 / 8$ & $0.004 L^{*}$ \\
\hline \multirow{4}{*}{ Egg-to-Adult Viability } & Oviposition Site & 2 & 5.6058 & $0.0053 * *$ \\
\hline & Maternal Infection Status & 1 & 0.0128 & 0.88 \\
\hline & Oviposition Site $*$ Maternal Infection & & & \\
\hline & Status & 2 & 0.528 & 0.5917 \\
\hline \multirow{5}{*}{ Clutch DCV Load } & Oviposition Site & 2 & 2.5523 & 0.0988 \\
\hline & Maternal Infection Status & 1 & 0.6277 & 0.4359 \\
\hline & Oviposition Site $*$ Maternal Infection & & & \\
\hline & & 2 & 1.4596 & 0.2522 \\
\hline & Status & & & \\
\hline
\end{tabular}

517

518 Table 2. Model outputs for statistical tests performed on all experiments testing the causes and costs

519 of infection avoidance in D. melanogaster adult oviposition. Significant predictors are marked with

520 asterisks $(\mathrm{p}<0.05=*, \mathrm{p}<0.01=* *$ and $\mathrm{p}<0.001=* * *)$. 


\section{Figure legends}

a

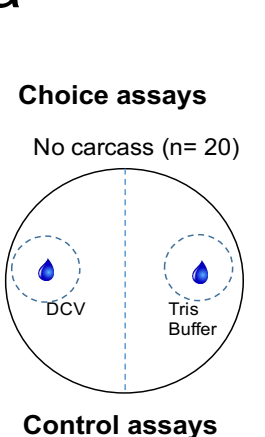

Larval

No carcass $(n=10)$

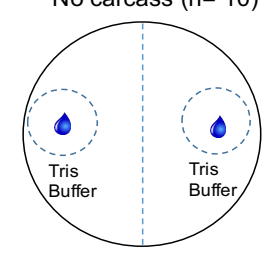

Female carcass $(n=28)$

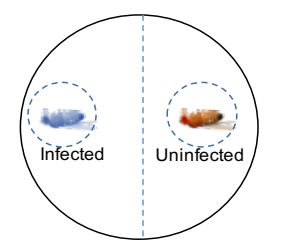

Female carcass $(n=10)$

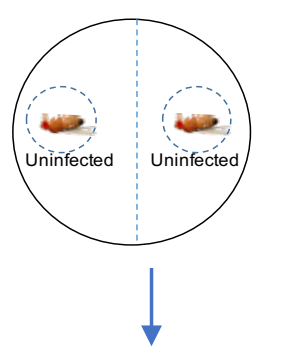

Egg-to-adult viability qPCR for DCV in eclosed adults

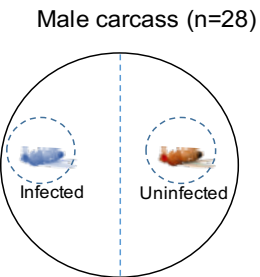

Male carcass $(n=10)$

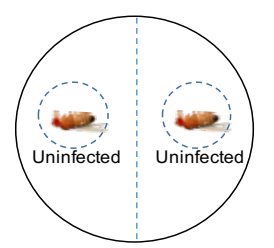

$b$
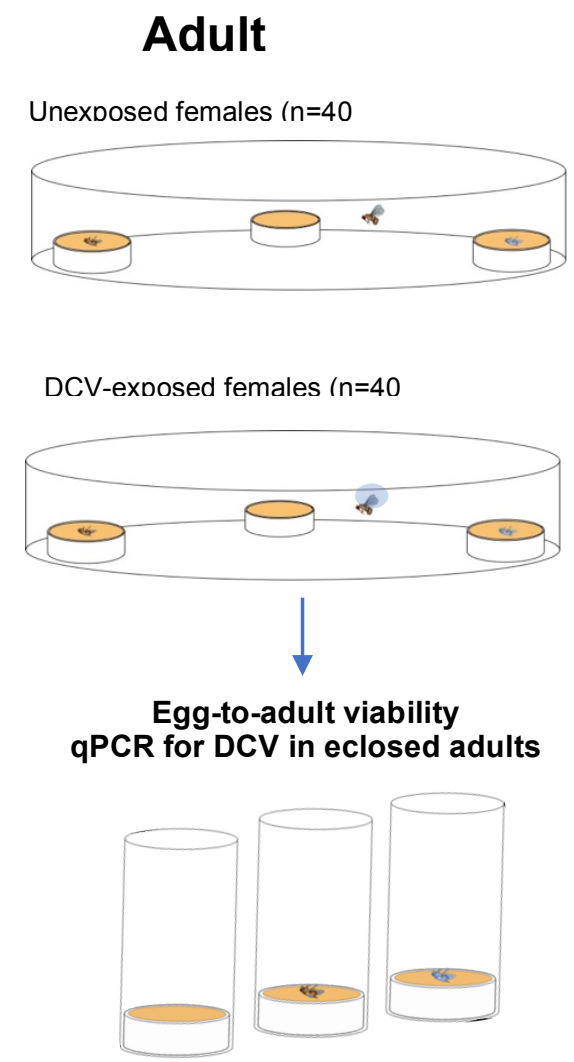

524 Figure 1 - Experimental design

525 (a) Two-choice chamber used to measure larval foraging choice when presented with

526 infectious and non-infectious food sources and the life-history data collected after the 72-

527 hour assay. Petri dishes were set up as either two-choice plates (containing an infectious and

528 non-infectious food source) or control plates (containing only non-infectious food sources).

529 Eggs were placed at the centre of each plate, allowed to hatch and left for 72 hours

530 whereupon the position of larvae was recorded to assay infection avoidance. (b) Three-choice

531 chamber used to assay oviposition site choice in infected and uninfected mothers when

532 presented with three sites containing just food, food and a fly carcass and food and an

533 infected fly carcass. The number of eggs laid at each site was measured twice at two 24 hour 
535 develop to adults whereupon the viral load of a randomly selected sub-sample was assayed.

536

(a)

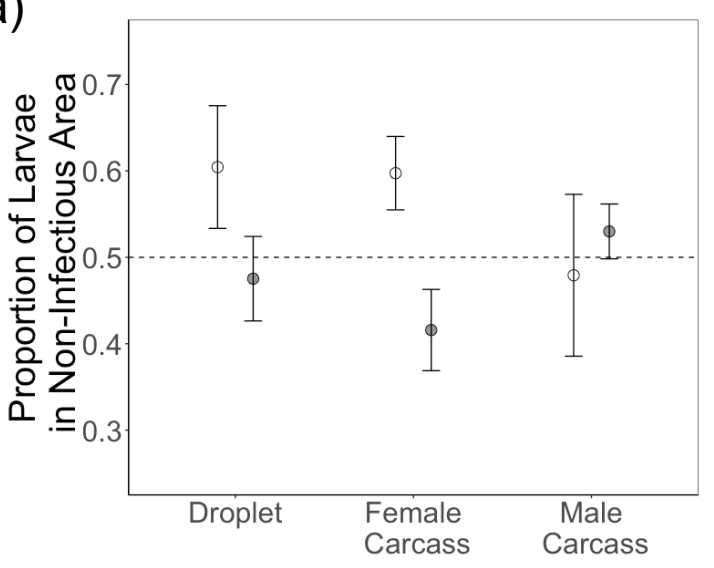

(b)

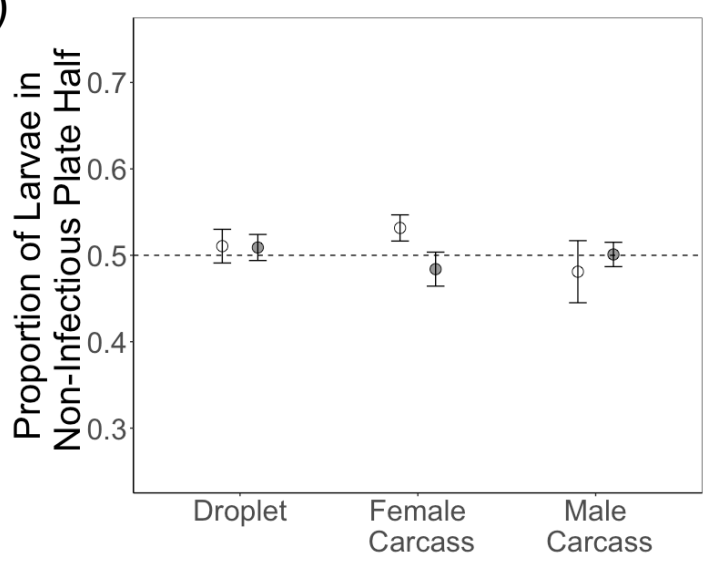

537

538 Figure 2 - Larval foraging choice

539 Mean \pm SE proportion of larvae on choice plates after 72 hours found (a) within area $2.2 \mathrm{~cm}$ in

540 diameter of the non-infectious food source and (b) on the non-infectious food source's half of

541 the plate. Results from both choice (white points) and control plates (grey points) are shown.

542 In the case of choice plates, where only non-infectious food sources are present, the

543 mean $\pm \mathrm{SE}$ is derived from the proportion of larvae present at a randomly selected side of the

544 plate. Food sources included droplets of TRIS, a male carcass or female carcass. 
(a)

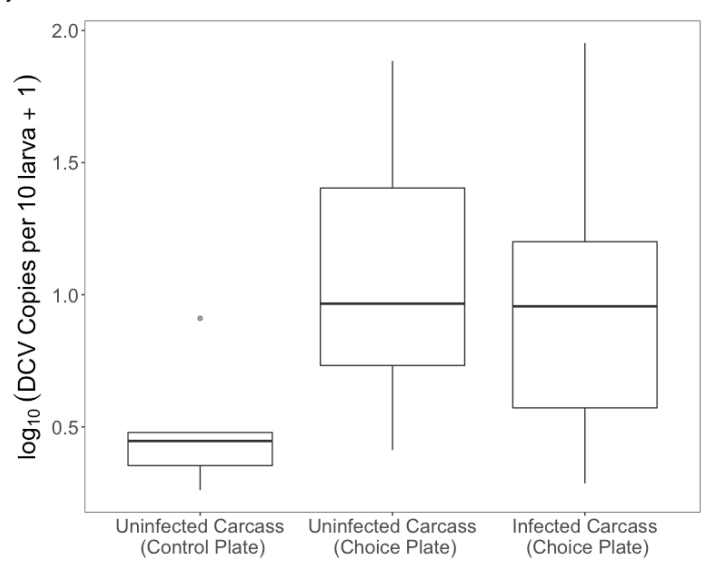

(c)

545

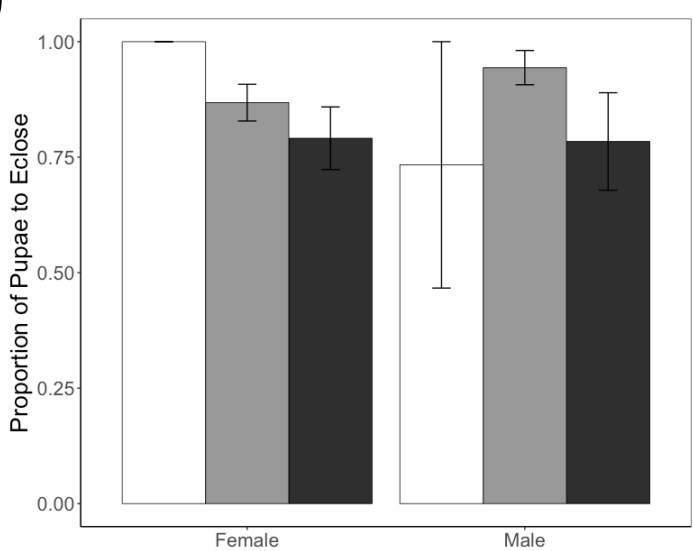

(b)

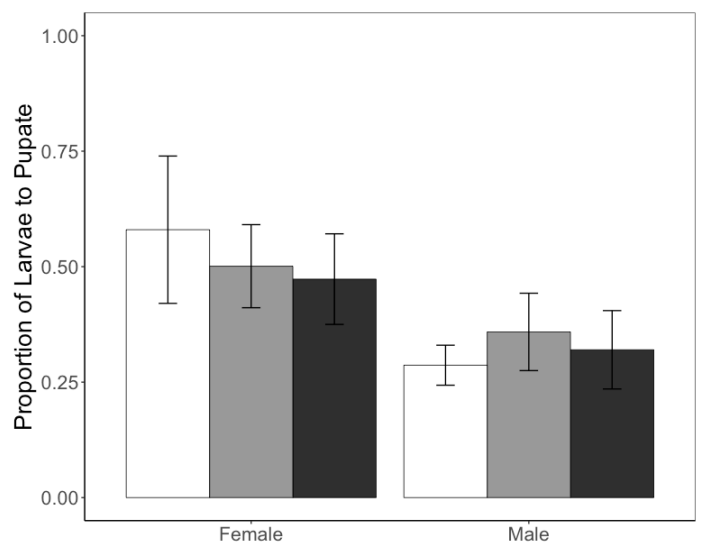

(d)

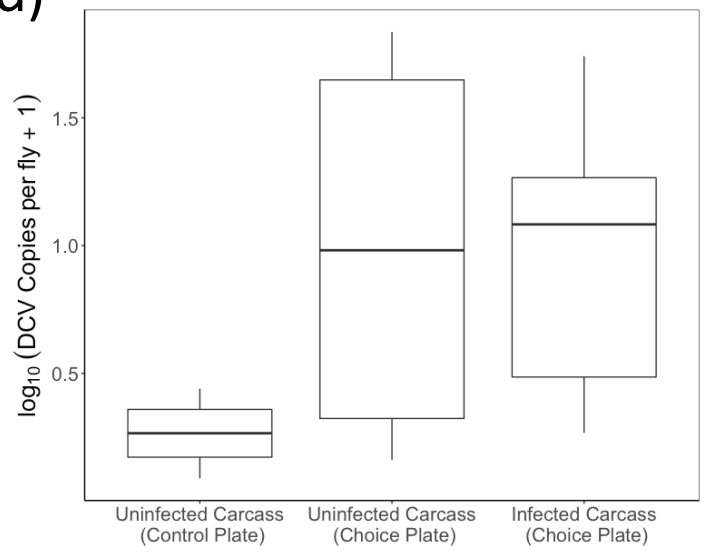

546 Figure 3. Fitness consequences of infectious scavenging

547 (a) The number of DCV copies present in larvae, quantified immediately after choice assays

548 having fed on an uninfected carcass on a control plate or a choice plate and an infected

549 carcass from a choice plate. Mean \pm SE proportion of larvae taken from carcass sites on both

550 choice and control plates to pupate (b) and (c) eclose. Larvae (and the subsequent pupae)

551 were taken from male and female carcasses and varied in their infectious status, an uninfected

552 carcass on a control plate (white bar), an uninfected carcass on a choice plate (grey bar) or an

553 infected carcass on a choice plate (black bar). (d) The number of DCV copies present in

554 adults derived from choice plate assays. 
(a)

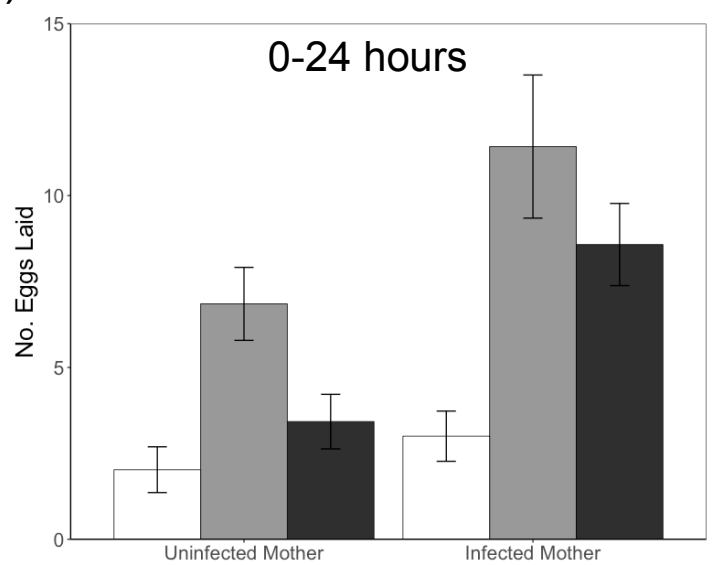

(c)

555

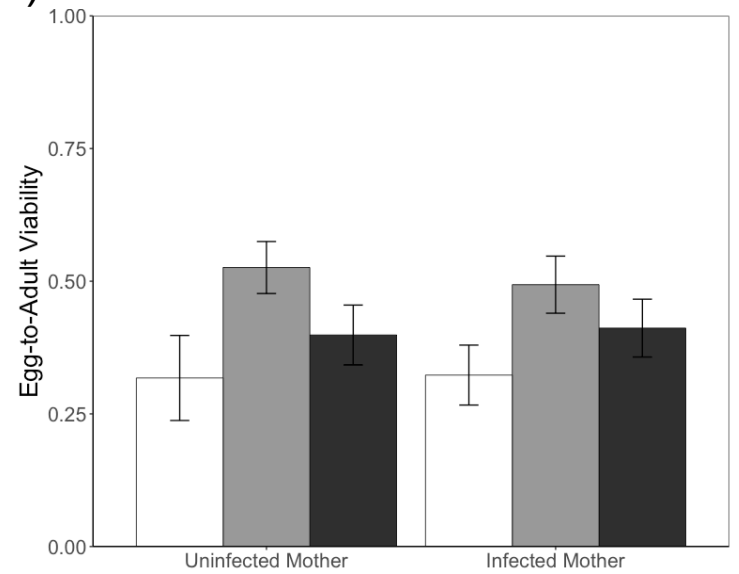

(b)

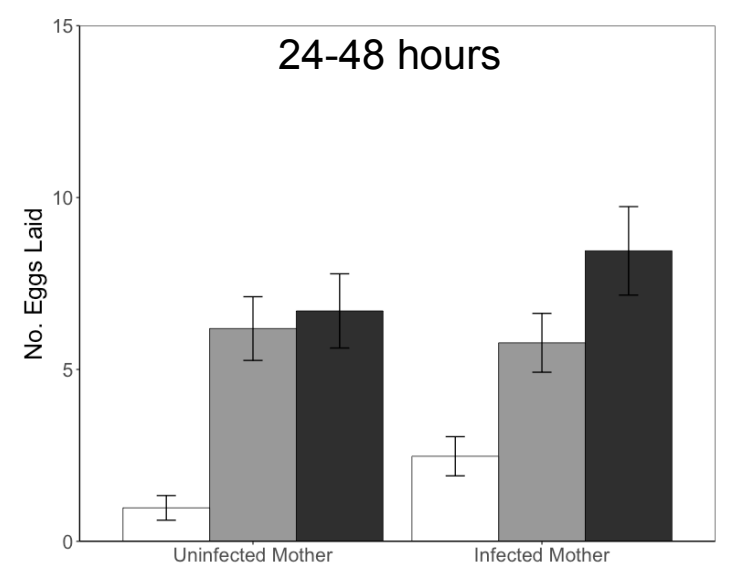

(d)

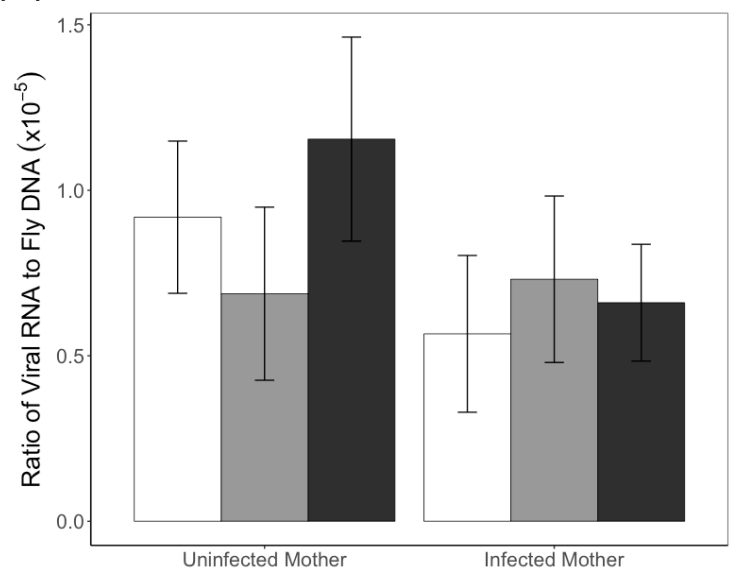

556 Figure 4. Adult oviposition choice and fitness consequences

557 The mean \pm SE number of eggs laid by infected and uninfected mothers at the three

558 oviposition sites after (a) the first 24 hours of the experiment and (b) the second 24-hour

559 period. (c) The mean \pm SE proportion of eggs to develop through to adulthood (egg-to-adult

560 viability) of the clutches laid during the oviposition site choice assay. (d) The mean $\pm \mathrm{SE}$

561 ratio of viral RNA to fly DNA in the clutches laid during the oviposition site choice assay.

562 Across all panels, oviposition site treatments are shown using the same colour scheme: food

563 only oviposition sites in white, food and uninfected carcass sites in grey and food and

564 infected fly carcass sites in black. 